[Agr. Biol. Chem., Vol. 32, No. 7, p. 888 893, 1968]

\title{
Aerobic Dissimilation of L-Rhamnose and the Production of L-Rhamnonic Acid and 1,2-Propanediol by Yeasts
}

\author{
By Toshiyuki Suzuki and Hiroshi OnIsHI \\ Noda Institute for Scientific Research, Noda-shi, Chiba-ken, Japan \\ Received December 27, 1967
}

\begin{abstract}
Aerobic dissimilation of L-rhamnose by various genera and species of yeasts was examined. Of 63 strains tested, 12 utilized L-rhamnose fairly well, and 7 strains, Debaryomyces klöckeri, Pichia pseudopolymorpha, P. rhodanensis, P. robertsii, P. wickerhamii, Candida polymorpha and Torulopsis famata, produced an appreciable amount of L-rhamnonic acid and/or 1,2-propanediol. These two main products were isolated in pure forms from the fermented broth of $C$. polymorpha and identified. Candida polymorph̆h produced L-rhamnonic acid and 1,2-propanediol from L-rhamnose in the presence of $\mathrm{CaCO}_{3}$ at good yield of $38 \%$ of sugar consumed.
\end{abstract}

In the previous papers, ${ }^{1 \sim 31}$ it was observed that the pattern of polyalcohol production in aerobic dissimilation of $\mathrm{D}$-galactose, $\mathrm{D}$-xylose, $\mathrm{L}$-arabinose or $\mathrm{D}$-ribose by various genera and species of yeasts was quite different from that with $\mathrm{D}$-glucose. For instance, Candida polymorpha produced D-arabinitol and erythritol from D-glucose, while the yeast produced galactiol from D-galactose, xylitol from D-xylose, L-arabinitol from L-arabinose and ribitol from D-ribose at good yield of $30 \sim 40 \%$ of sugar consumed. ${ }^{1 \sim 31}$ Pichia miso dissimilated D-xylose with the production of xylitol and two heptitols, though the yeast produced $D$ arabinitol, glycerol and erythritol from Dglucose. ${ }^{1,41}$

In the course of our studies on aerobic dissimilation of various sugars by yeasts, the authors observed that some yeasts utilized a methyl pentose, L-rhamnose, fairly well and gave two polyhydric products. This paper

1) H. Onishi, Bull. Agr. Chem. Soc. Japan, 24, 131 (1960).

2) H. Onishi and T. Suzuki, J. Bacteriol., 95, 1745 (1968).

3) H. Onishi and T. Suzuki, Agr. Biol. Chem., 30, 1139 (1966).

4) H. Onishi and M. B. Perry, Can. J. Microbiol., 11, 929 (1965). describes the pattern of L-rhamnose dissimilation by yeasts and the isolation and identification of the two major products, L-rhamnonic acid and 1,2-propanediol.

It has so far been reported that Bacterium rhamnosifermentans produced propylene $\mathrm{glycol}^{65}$ and Pasteurella pestis produced lactaldehyde ${ }^{61}$ from L-rhamnose but little has been known with yeasts.

\section{MATERIALS AND METHODS}

Yeast strains. The following 63 yeast strains were examined: Saccharomyces acidifaciens, Sacch. acidifaciens var. halomembranis, Sacch. rouxii, Sacch. rouxii var. halomembranis, Debaryomyces fabryi, Deb. gruetzii, Deb. hansenii, Deb. huderoi, Deb. klöckeri, Deb. mandschuricus, Deb. matruchoti, Deb. membranaefaciens, Deb. membranaefaciens var. Zingiberi, Deb. miso var. 1, Deb. sake, Deb. sake Forma 1, Deb. tyrocola, Pichia alcoholophila, $P$. belgica, $P$. farinosa, $P$. hyalospora, $P$. mandschurica, $P$. membranaefaciens, $P$. miso, $P$. polymorpha, $P$. pseudopolymorpha, $P$. quercibus, $P$. rhodanensis, $P$. robertsii, $P$. scolyti, $P$. wickerhamii, Hansenula anomala, $H$. anomala var. productiva, $H$. saturnus, $H$. schneggii, $H$. suaveolens, H. subpelliculosa, Candida albicans, C. arborea, C. guillermondii, C. krusei, C. parapsilosis, C. polymorpha, C.

5) A. J. Kluyver and C. H. Schnellen, Enzymologia, 4, 7 (1937).

6) E. Englesberg, J. Bacteriol., 74, 8 (1957). 
tropicalis, C. utilis, Torulopsis famata, T. halophila, T. nodaensis, $T$ sake, $T$. versatilis, Torula rubra, Kloeckera africana, Kl. apiculata, Trichosporon behrendii, Trich. cutaneum, Trigonopsis variabilis, Crytococcus albidus, Cry. laurentii, Cry. neoformans, Rhodotorula rosa, Monilia formosa, $M$. sitophila and $M$. vini. Among them, typical L-rhamnose-assimilating yeasts, ${ }^{7,8)}$ Pichia pseudopolymorpha, $P$. rhodanensis, $P$. robertsii, P. scolyti and $P$. wickerhamii were obtained through the courtesy of Dr J. Boidin Professor of Lyon University, France.
Medium and fermentation condition. Aliquots $(0.5 \mathrm{ml})$ of freshly cultured yeast suspension were inoculated into large test tubes each containing $8 \mathrm{ml}$ of a sterilized medium of the following composition: L-rhamnose monohydrate (Nutritional Biochemicals Corp.) $10 \%$, D-glucose $0.1 \%, \mathrm{KH}_{2} \mathrm{PO}_{4} 0.1 \%, \mathrm{MgSO}_{4}$ $.7 \mathrm{H}_{2} \mathrm{O} \quad 0.05 \%, \mathrm{CaCl}_{2} \cdot 2 \mathrm{H}_{2} \mathrm{O} \quad 0.01 \%, \mathrm{NaCl} 0.01 \%$, casamino acids (Difco) $0.4 \%$, yeast extract (Difco) $0.1 \%$, with or without the addition of $\mathrm{CaCO}_{3}(0.3$ $\mathrm{g}$ /tube). The tubes were shaken on a reciprocal

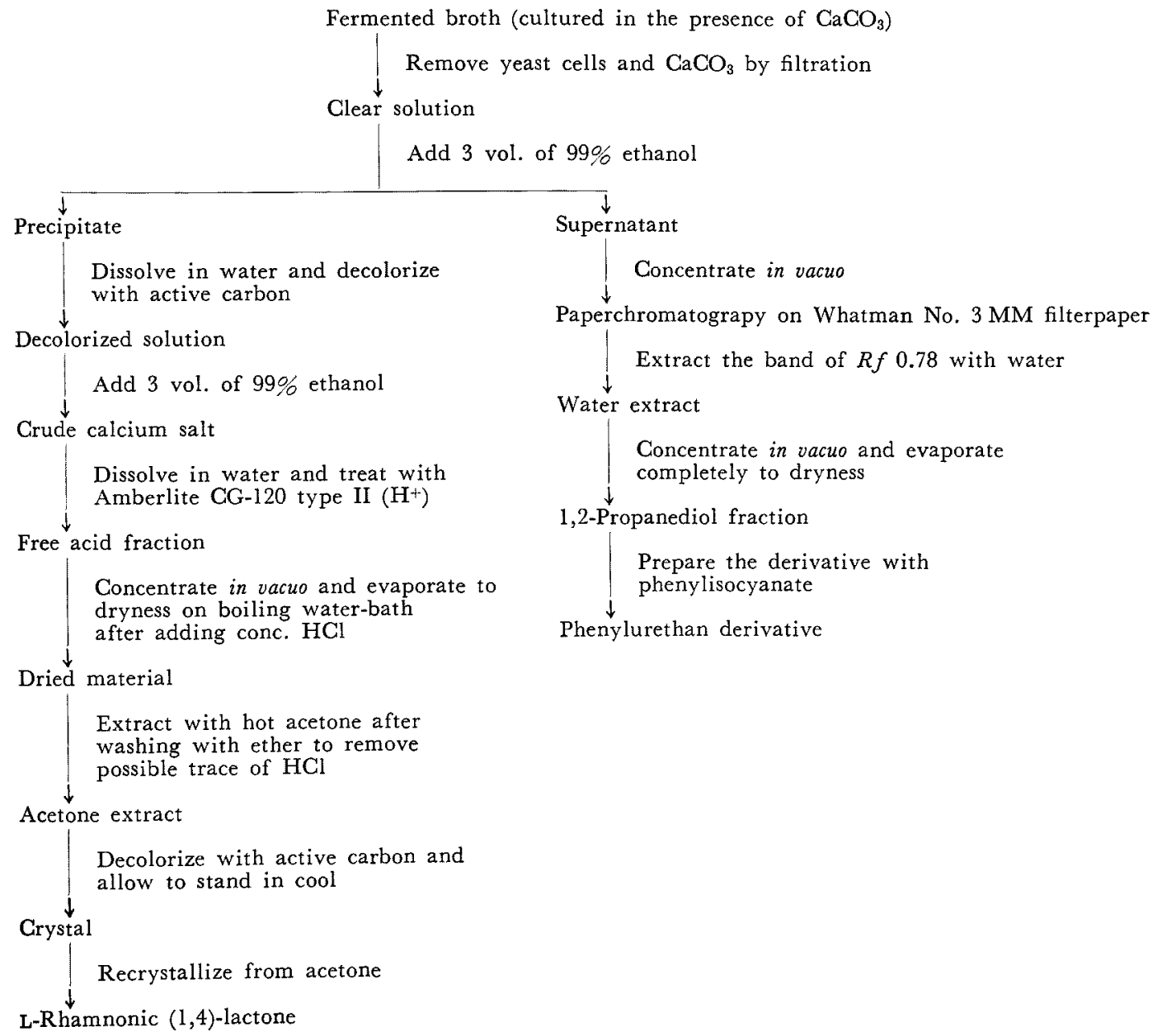

Add 3 vol. of $99 \%$ ethanol

Dissolve in water and decolorize with active carbon

Decolorized solution

Add 3 vol. of $99 \%$ ethanol

Crude calcium salt

Dissolve in water and treat with Amberlite CG-120 type II $\left(\mathrm{H}^{+}\right)$

Free acid fraction

Concentrate in vacuo and evaporate to dryness on boiling water-bath after adding conc. $\mathrm{HCl}$ $\downarrow$

Dried material

Extract with hot acetone after washing with ether to remove possible trace of $\mathrm{HCl}$

Acetone extract

Decolorize with active carbon and allow to stand in cool

Crystal

Recrystallize from acetone

L-Rhamnonic $(1,4)$-lactone

\section{Supernatant}

Concentrate in vacuo

Paperchromatograpy on Whatman No. $3 \mathrm{MM}$ filterpaper Extract the band of $R f 0.78$ with water

Water extract

Concentrate in vacuo and evaporate completely to dryness

1,2-Propanediol fraction $\downarrow$ Prepare the derivative with phenylisocyanate

Phenylurethan derivative

FIG. 1. Isotation and Purification Procedure of the Fermented Products from the Fermented Broth.

7) J. Boidin, M. C. Pignal, Y. Lehodey, A. Vey and F. Abadie, Bull. de la Soc. Mycol. de France, 80, 396 (1964). 
shaker operating at $300 \mathrm{rpm}$ with an amplitude of $2 \mathrm{~cm}$ at $30^{\circ} \mathrm{C}$ for $3 \sim 7$ days.

Analytical methods. After removal of the yeast cells by filtration, clear fermentation liquid was analyzed according to the method of Neish ${ }^{9}$ for reducing sugar and total polyalcohol. 1,2-Propanediol and glycerol were separately determined after fractionating by the celite column chromatography of Neish.101 Aldonic acid was assayed by the method of Hestrin'11 as the lactone after heating the fermented broth in the presence of $\mathrm{I} \mathrm{N} \mathrm{HCl}$ in a boiling water bath for $15 \mathrm{~min}$. In this case, pure L-rhamnonic $(1,4)$-lactone was used as a standard and the results were corrected for L-rhamnose interference. Paperchromatography was performed by the ascending method on Whatman No. 1 filterpaper using $n$-propanol-ethylacetate-water $(7: 1: 2 \mathrm{v} / \mathrm{v})^{12}$ as the mobile phase. The reducing sugar was detected with aniline hydrogen phthalate reagent ${ }^{13}$ ! and polyhydric compound with $\mathrm{KIO}_{4}$-tetra base by the method of Yoda.141 The lactone was detected with $\mathrm{NH}_{2} \mathrm{OH}-\mathrm{FeCl}_{3}$ by the method of Abdel-Akher and Smith.15)

Table I. Aerobic Dissimilation of L-Rhamnose and Production of Polyhydric COMPOUNDS BY VARIOUS YEASTS

Strains $\begin{array}{cc}\text { Presence } \\ \text { of } \mathrm{CaCO}_{3}\end{array} \begin{gathered}\begin{array}{c}\text { Fermen- } \\ \text { tation } \\ \text { period } \\ \text { (days) }\end{array}\end{gathered}$

Debaryomyces
huderoi

Deb, klöckeri Pichia
pseudopolymorpha $\{-$

$P$. rhodanensis

P. robertsii

P. scolyti

P. wickerhamii

Hansenula saturnas

Candida polymorpha

Torulopsis famata

Cryptococcus laurentii

Cry. neoformans

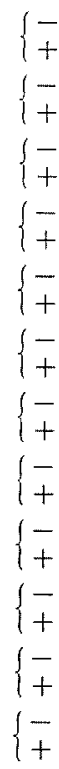

$\%$ of L-
rhamnose
consumed

$\begin{array}{cc} & \text { Yield of } \\ \% \text { of total } & \text { total } \\ \text { poly- } & \text { polyalcohol } \\ \text { alcohol } & \text { on L- }\end{array}$
produced panediol)

$\begin{array}{rr}3.90 & 0.29 \\ 6.02 & 0.65 \\ 4.48 & 0.92 \\ 8.33 & 1.63 \\ 10.23 & 0.92 \\ 8.59 & 1.60 \\ 6.28 & 0.05 \\ 10.84 & 0.52 \\ 7.69 & 0.17 \\ 9.94 & 0.45 \\ 7.61 & 0.07 \\ 6.10 & 0.05 \\ 9.15 & 0.82 \\ 9.65 & 2.56 \\ 8.11 & 0.11 \\ 6.23 & 0.10 \\ 5.77 & 1.82 \\ 9.35 & 1.83 \\ 4.00 & 0.29 \\ 9.41 & 0.25 \\ 6.03 & 0.10 \\ 9.04 & 0.09 \\ 7.95 & 0.06 \\ 8.16 & 0.06\end{array}$
rhamnose consumed panediol) (as 1,2-pro- $=0.78=0.54=0.41=0.31$
Polyhydric compounds of fermented broth*

\begin{tabular}{|c|c|c|c|c|}
\hline $\begin{array}{l}7.4 \% \\
10.8\end{array}$ & \pm & $\begin{array}{l}H+(H)^{\dagger} \\
H(H)\end{array}$ & - & - \\
\hline $\begin{array}{l}20.5 \\
19.6\end{array}$ & $\frac{t}{m}$ & $\begin{array}{l}\#(H) \\
H(H)\end{array}$ & - & $\stackrel{+}{+}$ \\
\hline $\begin{array}{r}9.0 \\
18.6\end{array}$ & $\stackrel{+}{+}$ & $\begin{array}{l}+(+) \\
+(H)\end{array}$ & - & $\overline{ \pm}$ \\
\hline $\begin{array}{l}0.8 \\
4.8\end{array}$ & $\overline{+}$ & $\begin{array}{l}\#(H) \\
-(-)\end{array}$ & - & $\stackrel{+}{+}$ \\
\hline $\begin{array}{l}2.2 \\
4.5\end{array}$ & $\overline{+}$ & $\begin{array}{l}W(H) \\
+(+)\end{array}$ & + & + \\
\hline $\begin{array}{l}0.9 \\
0.8\end{array}$ & - & $\begin{array}{l}H(H) \\
H(H)\end{array}$ & - & - \\
\hline $\begin{array}{r}9.0 \\
26.5\end{array}$ & + & $\begin{array}{l}H(H) \\
-(-)\end{array}$ & - & $\overline{ \pm}$ \\
\hline $\begin{array}{l}1.4 \\
1.6\end{array}$ & - & $\begin{array}{l}H(H) \\
H(H)\end{array}$ & \pm & + \\
\hline $\begin{array}{l}31.5 \\
19.6\end{array}$ & H & $\begin{array}{l}\#(+\#) \\
\#(+)\end{array}$ & - & $\frac{ \pm}{W}$ \\
\hline $\begin{array}{l}7.3 \\
2.7\end{array}$ & \pm & $\begin{array}{l}\text { W( }(\text { H) } \\
+(H)\end{array}$ & - & + \\
\hline $\begin{array}{l}1.7 \\
1.0\end{array}$ & - & $\begin{array}{l}\text { H(H) } \\
H(H)\end{array}$ & - & $\bar{t}$ \\
\hline $\begin{array}{l}0.8 \\
0.7\end{array}$ & - & $\begin{array}{l}H(H) \\
H(H)\end{array}$ & - & $\frac{-}{+}$ \\
\hline
\end{tabular}

Polyhydric compounds with $R f$ of $0.78,0.54$ and 0.31 are assumed to be 1,2-propanediol, Lrhamnitol-like compound and L-rhamnose, and L-rhamnoic acid, respectively. $-=$ no detectable spot, $H=$ intense spot.

$\dagger$ Parenthesis shows the spot of residual L-rhamnose.

9) A. C. Neish, "Analytical Methods for Bacterial Fermentations," 2nd Rev. National Research Council of Canada, N. R. C. No. 2952 (1952).

10) A. C. Neish, Can. J. Res., B28, 535 (1950).

11) S. Hestrin, J. Biol. Chem., 180, 249 (1949).
12) J. Cerbulis, Anal. Chem., 27, 1400 (1955).

13) S. M. Partridge, Nature, 164, 443 (1949).

14) A. Yoda, J. Chem. Soc. Japan, 73, 18 (1952).

15) M. Abdel-Akher and F. Smith, J. Am. Chem. Soc., 73, 5859 (1951). 
Isolation of fermentation products. Isolation and purification procedures of L-rhamnonic acid and 1,2-propanediol from the fermented broth are illustrated in Fig. 1.

Reagent. L-Rhamnonic (1,4)-lactone was prepared from L-rhamnose by the method of Jackson and Hudson.16!

\section{RESULTS}

I) Aerobic dissimilation of L-rhamnose and production of polyhydric compounds by various genera and species of yeasts

Of 63 yeast strains tested, 12 could utilize L-rhamnose fairly well and the analytical data of the fermented broth were shown in Table I. The paperchromatogram showed two main polyhydric products of $R f \quad 0.78$ and 0.31 . The spot of $R f 0.54$ corresponds to those of L-rhamnose and unknown product. Candida polymorpha, Debaryomyces klöckeri, Pichia pseudopolymorpha and $P$. wickerhamii produced a large amount of polyhydric compound of $R f$ value of 0.78 , and Candida polymorpha, Debaryomyces klöckeri, Hansenula saturnas, Pichia rhodanensis, $P$. robertsii and Torulopsis famata produced much polyhydric compound of $R f$ value of 0.31 . It was generally observed that the production of polyhydric compounds was enhanced by adding $\mathrm{CaCO}_{3}$ to the medium. On the other hand, Cryptococcus laurentii, Cry. neoformans and Pichia scolyti produced only a trace amount of polyhydric compound in spite of their good utilization of L-rhamnose.

As the fermented broth in the presence of $\mathrm{CaCO}_{3}$ of Hansenula saturnas containing appreciable amount of the only one product of Rf 0.31 gave negligible value in polyalcohol determination, the product did not seem to be polyalcohol and was presumed to be aldonic acid by the characteristic mauve color reaction after treating water extract of the spot with $1 \mathrm{~N} \mathrm{HCl}$. Therefore, the other product of $R f 0.78$ was supposed to be poly-

16) E. L. Jackson and C.S. Hudson, ibid., 52, $1270(1930)$.
TABle II. ANalytical Results of THE FERMENTED BROTH OF Candida polymorpha AND Pichia robertsii

\begin{tabular}{|c|c|c|c|c|}
\hline \multirow[b]{2}{*}{ Presence of $\mathrm{CaCO}_{3}$} & \multicolumn{2}{|c|}{$\begin{array}{l}\text { Candida } \\
\text { polymorpha }\end{array}$} & \multicolumn{2}{|c|}{$\begin{array}{l}\text { Pichia } \\
\text { robertsii }\end{array}$} \\
\hline & - & + & - & + \\
\hline $\begin{array}{l}\text { Fermentation period } \\
\text { (days) }\end{array}$ & 7 & 6 & 7 & 6 \\
\hline $\begin{array}{l}\% \text { of L-rhamnose } \\
\text { consumed }\end{array}$ & 5.44 & 10.84 & 7.62 & 8.82 \\
\hline $\begin{array}{l}\% \text { of total polyalcohol } \\
\text { produced (as 1,2- } \\
\text { propanediol) }\end{array}$ & 1.80 & 1.56 & 0.16 & 0.33 \\
\hline $\begin{array}{l}\text { Yield of total poly- } \\
\text { alcohol on L- } \\
\text { rhamnose consumed } \\
\text { (as 1,2-propanediol) }\end{array}$ & $33.1 \%$ & $14.4 \%$ & $2.1 \%$ & $3.7 \%$ \\
\hline $\begin{array}{l}\% \text { of pure 1,2-pro- } \\
\text { panediol produced }\end{array}$ & 1.55 & 1.19 & 0.09 & 0.33 \\
\hline $\begin{array}{l}\% \text { of total adonic acid } \\
\text { produced (as L- } \\
\text { rhamnonic acid) }\end{array}$ & 0.25 & 2.96 & 0.70 & 2.37 \\
\hline $\begin{array}{l}\text { Yield of total aldonic } \\
\text { acid on L-rhamnose } \\
\text { consumed (as L- } \\
\text { rhamnonic acid) }\end{array}$ & $4.6 \%$ & $27.3 \%$ & $9.2 \%$ & $26.9 \%$ \\
\hline
\end{tabular}

alcohol, and the $R f$ value agreed with that of 1,2-propanediol and was different from that of glycerol.

Next, more detailed analyses of two major products were carried out using the fermented broth of Candida polymorpha and Pichia robertsii, two excellent producers of polyhydric compounds, and the results were shown in Table II. As $76 \sim 86 \%$ of the total polyalcohol in the fermented broth of Candida polymorpha were recovered as pure 1,2-propanediol by celite column chromatography, 1,2-propanediol would be a major polyalcohol produced. Any polyalcohol could not be detected in the glycerol fraction after celite chromatography. The result shows that Candida polymorpha produced L-rhamnonic acid and 1,2-propanediol from L-rhamnose in the presence of $\mathrm{CaCO}_{3}$ at good yield of $38 \%$ of sugar consumed.

\section{II) Isolation and identification of L-rhamnonic acid and 1,2-propanediol}

The isolation of two major polyhydric products from the fermented broth of Candida 
polymorpha was carried out according to the procedure shown in Fig. 1.

a) Identification of L-rhamnonic acid. In aqueous solution, $4.86 \mathrm{~g}$ of crude calcium salt, obtained from $224 \mathrm{ml}$ of the fermented broth containing 2.70\% of aldonic acid (as L-rhamnonic acid), were treated with Amberlite CG120 type II $\left(\mathrm{H}^{+}\right)$and the resulted free acid was lactonized under the acidic condition with HCl. A yield of $0.69 \mathrm{~g}$ of crystalline lactone was obtained by three times recry-

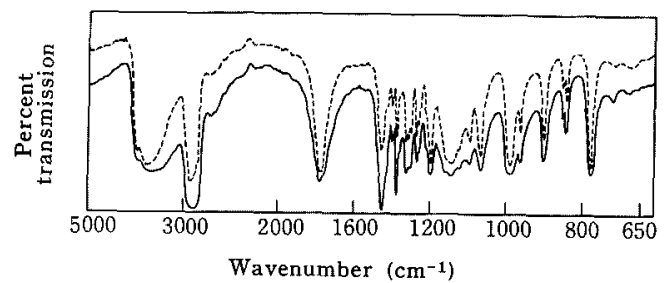

FIG. 2. Infrared Spectra of Isolated and Synthetic L-Rhamnonic (1,4)-lactone. (Nujol mull)

-----: Isolated crystal.

—: Synthetic L-rhamnonic $(1,4)$-lactone.

stallization of the lactone from acetone. The crystals showed $\operatorname{mp} 150 \sim 151^{\circ} \mathrm{C}$, which was undepressed to admix with synthetic L-rhamnonic $(1,4)$-lactone, and $[\alpha]_{\mathrm{D}}^{20}-37.9^{\circ}(c=4.33$, water, $20 \mathrm{~min}$ after solution). Anal. Found: $\mathrm{C}, 44.51 ; \mathrm{H}, 6.22 \%$. Calcd. for $\mathrm{C}_{6} \mathrm{H}_{10} \mathrm{O}_{5}: \mathrm{C}$, $44.45 ; \mathrm{H}, 6.22 \%$. The infrared spectrum of the crystals coincided with that of synthetic Lrhamnonic (1,4)-lactone (Fig. 2).

b) Identification of 1,2-propanediol. Polyalcohol fraction of $R f 0.78$ was purified by paperchromatography on Whatman No. $3 \mathrm{MM}$ filterpaper and the cut section was extracted with distilled water and the extract was evaporated in vacuo to dryness. The phenylurethan derivative was prepared from completely dried sample with phenylisocyanate. The crystals, obtained by crystallization from benzene and petroleum benzine, were found to be $\mathrm{mp} 149 \sim 150^{\circ} \mathrm{C}$, undepressed on admixture with the phenylurethan of authentic 1,2propanediol by the same preparation pro-

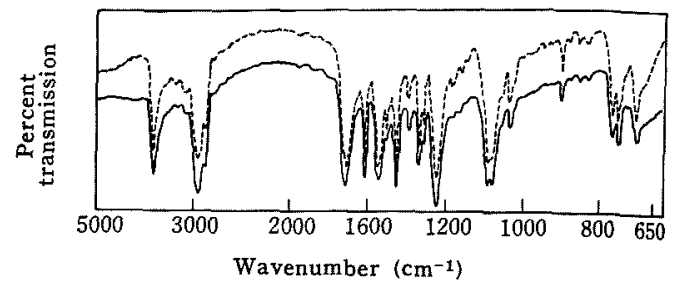

FIG. 3. Infrared Spectra of Isolated and Synthetic Phenylurethan of 1,2-Propanediol. (Nujol mull)

-.----: Crystalline derivative of the sample. diol.

cedure. Anal. Found: C, 65.01; H, 5.56; N, 9.25\%. Calcd. for $\mathrm{C}_{17} \mathrm{H}_{18} \mathrm{O}_{4} \mathrm{~N}_{2}: \mathrm{C}, 64.96 ; \mathrm{H}$, $5.77 ; \mathrm{N}, 8.91 \%$. The infrared spectrum of the crystals was superimposable with that of synthetic 1,2-propanediol phenylurethan (Fig. 3).

\section{DISCUSSION}

The fermentation product of L-rhamnose by yeasts has not so far been reported. In bacteria, Kluyver and Schnellen reported that Bacterium rhamnosifermentans produced propylene glycol from L-rhamnose, ${ }^{5 /}$ and Englesberg found that Pasteurella pestis accumulated a small amount of lactaldehyde from L-rhamnose. ${ }^{6)}$ It was also suggested that the L-rhamnose molecule was split into glyceraldehyde and lactaldehyde by Bacterium rhamnosifermentans, the latter being then reduced to propylene glycol. ${ }^{51}$ The metabolic pathway which leads to form dihydroxyacetone phosphate and L-lactaldehyde from L-rhamnose has been well established with the enzyme system of Escherichia coli. ${ }^{17-21 i}$ The present studies showed that yeasts produced 1,2-propanediol as the main metabolic product of

17) G. Tecce and M. DiGirolamo, Giorn. Microbiol, 1, 286 (1956).

18) D. M. Wilson and S. Ajl, J. Bacteriol., 73, 410,415 (1957)

19) Y. Takagi and H. Sawada, Biochim. Biophys. Acta, 92, 10, 18 (1964).

20) H. Sawada and Y. Takagi, ibid., 92, 26 (1964).

21) T. H. Chiu and D.S. Feingold, ibid., 92, 489 
L-rhamnose.

As for the biological formation of L-rhamnonic acid from L-rhamnose, only the formation by buckwheat seedlings and other seedlings has been found. ${ }^{22 !}$ This paper would be the first demonstration of microbial formation of L-rhamnonic acid.

Candida polymorpha and Pichia robertsii produced a large amount of L-rhamnonic acid, an oxidation product of L-rhamnose, in the presence of $\mathrm{CaCO}_{3}$, but L-rhamnitol corresponding to a reduction product of L-rhamnose was not found, instead 1,2-propanediol being produced. The authors have found that Pichia quercibus produced both xylitol, a reduction product, and $\mathrm{D}$-xylonic acid, an oxidation product of $\mathrm{D}$-xylose, by aerobic dissimilation of $\mathrm{D}$-xylose at rather good yield. ${ }^{231}$

22) G. A. Barber and W. Z. Hassid, Bull. Res. Council Israel Sect. A. 11, 249 (1963).

23) T. Suzuki and H. Onishi, Agr. Biol. Chem., 31, 1233 (1967).
However, the small spot of $R f 0.54$ was still detected on the paperchromatogram after removing residual $\mathrm{L}$-rhamnose from the fermented broth of Candida polymorpha, and careful examination is now going on to identify this L-rhamnitol-like product.

Acknowledgements. The authors wish to express their sincerest thanks to Prof. K. Arima and Prof. Y. Ikeda of the University of Tokyo for their kind guidance and to Prof. J. Boidin of University of Lyon, France, for his kind supply of yeast strains. The authors also wish to thank Dr. M. Mogi and Dr. N. Iguchi of this Institute for their encouragements and Mr. K. Kouchi for his technical assistance. 